\title{
Comparing the Effects of Cumin, Peppermint, and Milk of Magnesia on Gastrointestinal Complications after Caesarean Section
}

\author{
Maryam Tofighi Niaki ${ }^{1}$, Zoleykha Atarod ${ }^{2}$, Shabnam Omidvar ${ }^{3}$, Mandana Zafari ${ }^{1}$, Azar Aghamohammadi ${ }^{1}$, \\ Tahereh Asadi ${ }^{4} \&$ Taiebeh Rastegar ${ }^{5}$ \\ ${ }^{1}$ Faculty Member of Islamic Azad University, Sari Branch, Department of Midwifery, Sari Branch, Islamic Azad \\ University, Sari, Iran \\ ${ }^{2}$ Obstetrics \& Gynecology, Faculty Member of Mazandaran University of Medical Science, Sari, Iran \\ ${ }^{3}$ Reproductive Health, Faculty of Medicine, Babol University of Medical Sciences, Iran \\ ${ }^{4}$ Midwife of Emam Khomeyni Hospital, Sari, Iran \\ ${ }^{5}$ Midwife, Sari, Iran \\ Correspondence: Maryam Tofighi Niaki, Faculty Member of Islamic Azad University, Sari Branch, Department \\ of Midwifery, Sari Branch, Islamic Azad University, Sari, Iran. Tel: 98-91-1321-4472. E-mail: \\ m_tofighi2004@yahoo.com
}

Received: January 18, 2016 Accepted: February 25, 2016 Online Published: April 29, 2016

doi:10.5539/gjhs.v8n12p78 URL: http://dx.doi.org/10.5539/gjhs.v8n12p78

\begin{abstract}
Context: Gastrointestinal problems are common after Cesarean section. During the past three decades, there has been an increasing trend in the use of herbal plants in the treatment of various medical conditions.

Aims: This study aimed to compare the effects of cumin, peppermint with magnesium hydroxide (milk of magnesia; MOM) on gastrointestinal complications of Caesarean section.

Settings and Design: This randomized double-blind controlled trial was conducted in the Gynecology and Obstetrics Department of Imam Hospital (affiliated to Mazandaran University of Medical Sciences, Sari, Iran) during November 2013-August 2014. The project was approved by the Research Ethics Committee of Islamic Azad Medical University, Sari Branch (Iran).

Material and Methods: A total of 83 patients undergoing non-emergency Cesarean delivery in Imam Hospital were randomly selected. Patients with underlying diseases, history of gastrointestinal problems, fever, intestinal adhesion, longer-than-usual Cesarean section, and lack of cooperation were excluded. The subjects were informed about the study objectives and procedure and asked to provide written informed consent. They were then randomly assigned into three groups of cumin, peppermint, MOM. Gastrointestinal complications were assessed 20, 40, 60, and 120 minutes after drug administration.
\end{abstract}

Statistical Analysis Used: The collected data were analyzed using Fisher's exact and chi-square tests in SPSS for Windows 18.0.

Results: There was no significant difference between three groups according to incidence of gastrointestinal side effects after Cesarean section at the mentioned intervals.

Conclusions: Cumin and peppermint were as effective as MOM.

Keywords: cumin, peppermint, magnesium hydroxide, gastrointestinal complications, caesarean section

\section{Introduction}

Cesarean section is a major surgery performed by making incisions on a woman's abdomen and uterus to deliver a baby. Although the number of Cesarean sections in the US was on the rise for 12 years, the rates among singleton births remained stable during 2009-11 (31.3\%). A previous study in the US indicated a relation between Cesarean section rates and gestational age, i.e. while the rates decreased by over 5\% among deliveries at 38 weeks of gestation, a $4 \%$ increase was seen among deliveries occurring at the $39^{\text {th }}$ week of pregnancy. The same research indicated that about one-third of pregnancies in the country would end up with a Cesarean section (Osterman \& Martin, 2013). 
According to the World Health Organization, the rate of cesarean section delivery should not exceed $15 \%$ of total deliveries (Mohammaditabar, Kiani, \& Heydari, 2009) while the recent studies, the rate of caesarean is increasing in the Universe, so this rate is about 22\% in USA, 25\% in Brazil, 27\% in Chili and about $17-40 \%$ in 19 countries in Latin America (Hopkins, 2000; Murray, 2000). Although available statistics suggest a growing trend in Cesarean section rates in many countries of the world, including Iran, the existing data from Iran is not only inadequate, but also limited to short periods of time (Badakhsh et al., 2012; Ahmad Nia et al., 2009).

Based on statistics published in 1355, Caesarean section rate was19.5\%in comparison with year 2006 which was 42.3\% (Shareferad, Fathean, Terane, \& Mahake, 2007).

According to the results of different studies, Incidence of caesarean is very high in Iran (Torkzahrani, 2008; Shareferad, Fathean, Terane, \& Mahake, 2007; Bani, Rasouli, Ghorashi, Ghojazadeh, \& Hassanpour, 2010) and this rate was reported $26 \%$ up to $60 \%$ in comparison with some private institute which was reported up to $87 \%$ (Shareferad, Fathean, Terane, \& Mahake, 2007).

However, based on research in 1997, the cesarean section rate was reported as 19.5\% in Iran. The Highest rate of it goes for Qom province and the lowest rate of it goes for Sistan Baluchestan (Ministry of Health and Medical Education Report, 2014).

Gastrointestinal complications are common after most surgeries including Cesarean sections (Potter \& Perry, 2010). It is associated with several changes in central nervous system, leading to decreased bowel movements and driven problems among women (Hirayama et al., 2006). Postoperative ileus is one of The biggest problems of post-abdominal surgery along with abdominal cramp, abdominal distension, inability to start oral feeding, breastfeeding, and eventually increases the cost of hospital care (Akhlaghi et al., 2008). Normalization of the bowel, characterized by symptoms such as bowel sounds, first flatus or stool, and feeling of hunger, (Yaghmaei, Arbabi, Mokhtari, \& Behzadian, 2009). Herbs have been historically used to treat various conditions in humans. In fact, all medicines were derived from natural resources, mainly plants, until the $19^{\text {th }}$ century. While countries rich in herbs have always tended to use herbal medicines for the treatment of different medical conditions, there has been a global upward trend in the use of herbal plants and traditional medicine over the past three decades (Koocheki \& Nadjafi, 2003). Cumin, either green or black, has been widely administered as a remedy for indigestion, flatulence, bloating, and diarrhea in traditional and veterinary medicine (Chand, M. Jain, \& S. Jain, 2000). The fixed and essential oils, saponin, alkaloids, and proteins available in cumin seeds are responsible for their stimulant, carminative, and astringent properties. The active constituents of cumin extracts (e.g. volatile oil and thymoquinone) have been shown to prevent nephrotoxicity and hepatotoxicity caused by different diseases or exposure to harmful chemicals. In addition to its ability to increase respiration, cumin oil is known to have anti-inflammatory, analgesic, antipyretic, antimicrobial, antihypertensive, and antineoplastic (anti-tumor) properties. Changes in complete blood count, i.e. higher packed cell volume and hemoglobin, along with reductions in plasma levels of cholesterol, triglycerides, and glucose were seen in rats treated with cumin extract for up to 12 weeks (Ali \& Blunden, 2003)

Peppermint is commonly used in the preparation of herbal teas. The plant has been found to have substantial antineoplastic, antimicrobial, antiviral, and antioxidant properties plus a possible antiallergenic effect in vitro. According to studies on animal models, peppermint can exert not only a soothing effect on the gastrointestinal tract, but also analgesic/anesthetic effects on the central and peripheral nervous systems. Moreover, a number of clinical trials have indicated the beneficial effects of peppermint essential oil in patients with irritable bowel syndrome (IBS) (McKay \& Blumberg, 2006). The strong flavor, fresh scent, therapeutic properties, and cooling sensation of peppermint oil have turned it into a popular component of cosmetic, pharmaceutical, personal hygiene, and food products. This essential oil is thus broadly utilized in aromatherapy and the production of bath oils, mouthwashes, toothpastes, and topical ointments. Despite its positive effects, the application of peppermint oil is sometimes associated with allergic reactions (e.g. contact dermatitis) especially in those with perioral and intraoral disorders (Herro \& Jacob, 2010).

Antacids, a common group of over-the-counter drugs, contain different combinations of calcium, magnesium, and aluminum salts. They can relieve the symptoms of indigestion through the neutralization of gastric acid and inactivation of pepsin (a proteolytic enzyme). They, however, change gastric $\mathrm{pH}$ and hence interact with several other drugs by interfering with their dissolution and metabolism (Maton \& Burton, 1999). Despite the safety, accessibility, and inexpensiveness of cumin and peppermint, there is a lack of clinical evidence about the effects of these herbs on gastrointestinal complications after Cesarean section. Therefore, the present study investigated the efficacy of cumin, peppermint, and magnesium hydroxide in preventing gastrointestinal complications after Cesarean sections. 


\section{Materials and Methods}

\subsection{Participants}

A total of 83 women undergoing non-emergency Cesarean delivery were randomly selected. Non cooperative individuals and those with known underlying diseases, history of gastrointestinal problems, fever, intestinal adhesion, and longer-than-usual Cesarean section (which could confound postoperative gastrointestinal complications) were excluded. The participants matched in terms of duration of Cesarean section and having a normal body mass index $\left(19-26 \mathrm{~kg} / \mathrm{m}^{2}\right)$. All subjects were informed about the study objectives and protocol and their right to withdraw at any time. They were then asked to provide written informed consent.

Inclusion criteria: Pregnancy without complications, singleton baby, gestational age (38-42 w), No blood transfusion, repeated cesarean section, Normal BMI, and general anesthesia.

\subsection{Study Design}

This randomized, double-blind controlled trial was conducted in the Gynecology and Obstetrics Department of Imam Hospital (a university teaching hospital affiliated to Mazandaran University of Medical Sciences, Sari, Iran) during November 2013-August 2014. The study was approved by the Research Ethics Committee of Islamic Azad Medical University, Sari Branch, Iran. The trial protocol was registered in the Iranian Registry of Clinical Trials (ID: IRCT2014062918280N1; www.irct.ir) and performed in accordance with the Declaration of Helsinki and its subsequent revisions.

The subjects were randomly allocated to three groups to receive cumin, peppermint, or milk of magnesia (MOM). Twenty four hours after Cesarean section, the patients started their normal diet with tea (hospital routine). The first group was provided with oral cumin drops (Barij Essence Company, Iran) containing cuminaldehyde, gamma-Terpinene, beta-Pinene, and p-Cymene as effective ingredients. The same volume of oral peppermint essential oil drops (Barij Essence Company, Iran), containing menthol, menthone and methyl acetate, was provided to the second group. The third group received oral MOM (Lax-Mel, Tolid-Darou Pharmaceutical Company, Iran). The two herbal medicines were diluted (40 drops in $30 \mathrm{cc}$ tap water) and administered at three 20-minute intervals. Their effects were then compared with MOM $(30 \mathrm{cc})$ which is the routine medicine to reduce gastrointestinal complications after Cesarean section. A research assistant used a dropper to pour the medicines in similar graduated containers. Since the three medicines were similar in appearance, the researchers and patients remained unaware of the grouping.

All patients were visited at the end of each 20-minute interval and 120 minutes after the first drug administration. They were asked about the incidence of nausea, vomiting, heartburn, flatulence, incomplete defecation, belching, and bloating. Their responses were recorded in a questionnaire containing pre-, intra-, and postoperative information (including the mentioned symptoms). The data were then organized in separate data collection sheets for each group.

\subsection{Statistical Analysis}

The collected data were encoded and analyzed using Fisher's exact and chi-square tests. All analyses were performed in SPSS for Windows 18.0 (SPSS Inc., Chicago, IL, USA) at the $\mathrm{P}<0.05$ significance level.

\section{Results}

A total of 90 women who were referred to the hospital for a Cesarean section were screened during the study period. Since five patients did not meet the inclusion criteria and two were unwilling to participate, 83 patients were finally recruited and allocated to three groups. None of the patients dropped out of follow-up (Figure 1). 


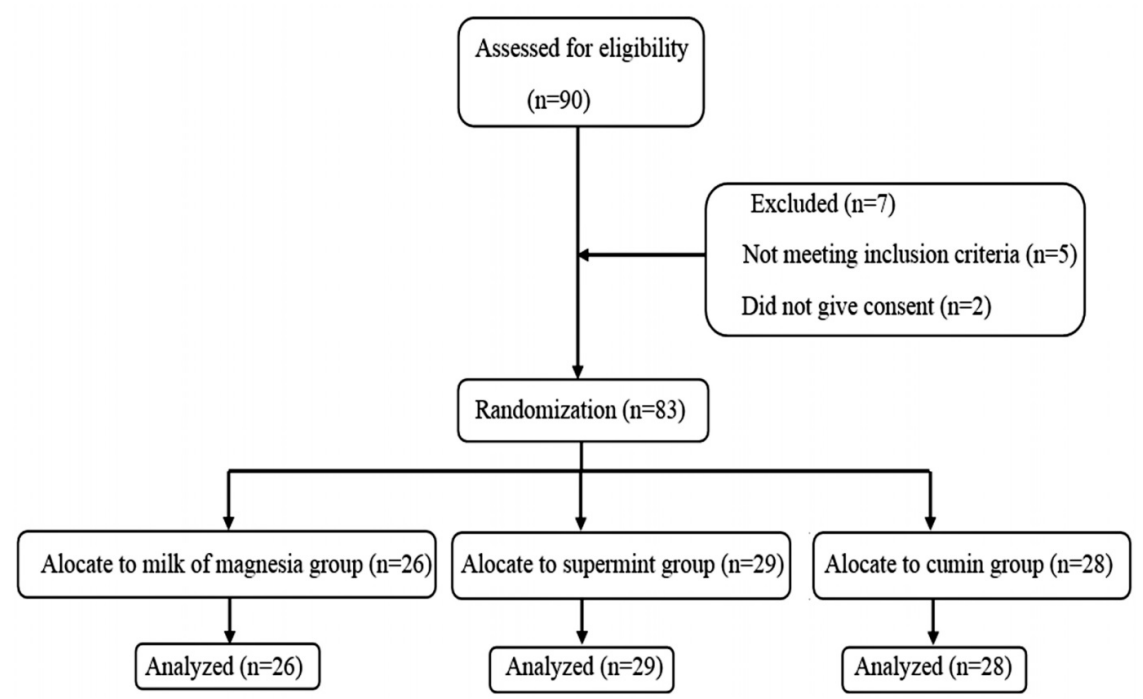

Figure 1. The CONSORT flow diagram of the study

The mean ages of the cumin, peppermint, and MOM groups were $27.76 \pm 4.29,28.12 \pm 4.29$, and $26.56 \pm 4.60$ years, respectively $(\mathrm{P}>0.05)$ (Table 1$)$.

Table 1. The mean age of subjects in different groups of intervention

\begin{tabular}{llll}
\hline Groups & Mean & SD & $\mathrm{p}_{\mathrm{v}}$ \\
\hline Cumin & 27.7600 & 4.28447 & \\
$\mathrm{~N}=25$ & & & \\
$\begin{array}{l}\text { Pepermint } \\
\mathrm{N}=27\end{array}$ & 28.1111 & 4.28174 & 0.419 \\
$\mathrm{MOM}$ & 26.5600 & 4.59239 & \\
$\mathrm{~N}=25$ & & & \\
\hline
\end{tabular}

Moreover, the three groups had no significant differences in terms of body mass index (BMI), number of deliveries and pregnancies, duration of Cesarean section, and gestational.

Postoperative evaluations revealed that the three groups were not significantly different in the incidence of symptoms 20 minutes after drug administration. However, all medicines could effectively reduce the complications (Table 2). We could not find significant differences forty and 60 minutes after intervention in all the three groups as well.

Table 2. The effects of cumin, peppermint, and milk of magnesia (MOM) on gastrointestinal complications 20 minutes after drug administration

\begin{tabular}{lllll}
\hline Complication & $\begin{array}{l}\text { Cumin } \\
\mathbf{N = 2 8}\end{array}$ & $\begin{array}{l}\text { Peppermint } \\
\mathbf{N = 2 9}\end{array}$ & $\begin{array}{l}\text { MOM } \\
\mathbf{N = 2 6}\end{array}$ & \multirow{2}{*}{ Pv } \\
\hline Nausea & $3.6 \%$ & $6.9 \%$ & $0 \%$ & 0.404 \\
\hline Vomiting & $0 \%$ & $0 \%$ & $0 \%$ & -- \\
Heartburn & $17.9 \%$ & $20.7 \%$ & $7.7 \%$ & 0.385 \\
Flatulence & $14.3 \%$ & $10.3 \%$ & $11.5 \%$ & 0.897 \\
Incomplete defecation & $92.9 \%$ & $89.7 \%$ & $96.2 \%$ & 0.649 \\
Bloating & $25.0 \%$ & $17.2 \%$ & $7.7 \%$ & 0.236 \\
Belching & $25.0 \%$ & $27.6 \%$ & $15.4 \%$ & 0.532 \\
\hline
\end{tabular}


Two hours after drug administration, a significant difference in the incidence of flatulence was observed between groups (Table 3).

Table 3. The effects of cumin, peppermint, and milk of magnesia (MOM) on gastrointestinal complications 120 minutes after drug administration

\begin{tabular}{lllll}
\hline Complication & $\begin{array}{l}\text { Cumin } \\
\mathbf{N}=\mathbf{2 8}\end{array}$ & $\begin{array}{l}\text { Peppermint } \\
\mathbf{N = 2 9}\end{array}$ & $\begin{array}{l}\text { MOM } \\
\mathbf{N = 2 6}\end{array}$ & $\mathbf{P}_{\mathbf{v}}$ \\
\hline Nausea & $0 \%$ & $0 \%$ & $0 \%$ & --- \\
\hline Vomiting & $0 \%$ & $0 \%$ & $0 \%$ & --- \\
\hline Heartburn & $0 \%$ & $0 \%$ & $0 \%$ & --- \\
\hline Flatulence & $50.0 \%$ & $17.2 \%$ & $38.5 \%$ & 0.031 \\
\hline Incomplete defecation & $71.4 \%$ & $58.6 \%$ & $61.5 \%$ & 0.577 \\
\hline Bloating & $3.6 \%$ & $3.6 \%$ & $3.8 \%$ & 0.998 \\
\hline Belching & $60.7 \%$ & $51.7 \%$ & $38.5 \%$ & 0.260 \\
\hline
\end{tabular}

As the table exhibits, there was a mild difference between cumin and peppermint groups in flatulence after 120 minutes after intervention. Otherwise we could not find significant differences/between three groups in other complications.

\section{Discussion}

Avicenna, a famous Persian physician commonly called the father of modern medicine, used herbs in $75 \%$ of his medicines. The great success of his remedies confirms the effectiveness of herbal medicines (Saad, Azaizeh, \& Said, 2008).

Herbs available in Iran can be effective on the treatment of neurological, cardiovascular, gastrointestinal, respiratory, and skin diseases. Moreover, herbs such as cinnamon, Silybum marianum, garlic, Nigella, and Echium are believed to attract more attention in the production of future anti-free radical drugs (Hasani \& Ranjbar, 2009). Present study has shown that herbal medicines are as effective as chemical medicines.

Zoorob showed that an herbal preparation to relieve inflammation and smooth muscle contraction was also effective in treating gastrointestinal complications and painful abdominal spasms (Zoorob, 2012). A multinational study on the use of herbal medicines during pregnancy indicated their high popularity among women. However, women of different regions tended to use different types of herbs to remedy pregnancy-related health issues. The authors finally asserted the need for more accurate knowledge about the efficacy and safety of herbal medicines in pregnancy (Holst, Wright, Haavik, \& Nordeng, 2009). In addition, while patients generally take herbal supplements in combination with conventional drugs (Liu et al., 1997; Abebe, 2002), some researchers discuss that herbal medicines should be cautiously administered to prevent any possible adverse drug-herb interactions or complications such as bleeding (Hepner, 2002).

Furthermore, due to their few side effects, herbal medicines have long been administered and even commercially produced in various forms, especially extracts (Bandaranayake, 2006).

Cumin is well accepted as a carminative herb in traditional Iranian medicine (Bahmani et al, 2014). A study on patients with IBS suggested the capability of cumin extract to significantly reduce abdominal pain, bloating, incomplete defecation, fecal urgency, and presence of mucus in stool (Agah et al., 2013). A study on mice revealed the high antioxidant capacity and antimalarial properties of Nigella sativa (black cumin) seeds (Okeola \& Oluwatosin, 2011). Similar to our findings, a previous study reported cumin and MOM to have comparable effects on preventing gastrointestinal complications after Cesarean section (Sakhavar \& Mirteymouri, 2009). Cumin can treat bloating and dyspepsia by promoting intestinal peristalsis and facilitating the excretion of waste material from the stomach and intestines (Singh \& Goswami, 1998). Despite the mentioned beneficial effects of cumin, Fazel et al. reported cumin oil to have minor effects on bleeding after Cesarean section (Fazel, Esmaeili, \& Razavi, 2013).

Around the world, such as India, Europe, Arabic countries and Iran Black cumin seeds and oil are traditionally used in the treatment of some disease such as fever, asthma, hypertension, gastrointestinal disorders, inflammation, tumor, cough, bronchitis, headache, eczema, dizziness, impotence, Dysmenorrhea and flu (Ali \& Blunden, 2003).

The beneficial effects of herbal medicines, especially cumin and its constituents have been shown by clinical 
studies, from which hypotension (Khattab \& Nagi, 2007; Dehkordi \& Kamkhah, 2008), hypoglycemic (Kaleem et al., 2006; Meddah et al., 2009), hypolipidemic (Bamosa, Ali, \& Al-Hawsawi, 2002), antioxidant (Uz et al., 2008; Kanter, Coskum, \& Uysal, 2006) anti-inflammatory (Al-Ghamdi, 2001) and anti-tumor (Mbarek, 2007; Al-Johar, 2008) effects can be noted. It is also used as diuretic, anti-parasitic and carminative agent (Ali \& Blunden, 2003).

The antimicrobial, antiviral, antioxidant, antitumor, and antiallergenic properties of peppermint have been established in vitro (McKay \& Blumberg, 2006). Moreover, considering the relaxing effects of peppermint on the gastrointestinal tissue, analgesic and anesthetic effects in the central and peripheral nervous system too. Many stomach relaxers contain peppermint. The Food and Drug Administration (FDA), however, does not seem to examine these products with the same scrutiny used for conventional drugs. Cappello et al. (Cappello et al., 2007) and Kingham (Kingham, 1995) showed that peppermint essential oil could relieve abdominal pain by reducing smooth muscle spasm in the gastrointestinal tract. In the current study, peppermint oil could significantly decrease heartburn, constipation, and belching. Studies on the efficacy of peppermint oil in the treatment of IBS have indicated contradictory results. Since peppermint oil is assumed to be less effective on other gastrointestinal conditions, the accidental recruitment of people with symptoms of IBS caused by other conditions might have been responsible for such inconsistencies (Alam et al., 2013).

Micklefield et al. showed that a mixture of cumin and mint was effective on relaxing the smooth muscles of the intestine and reducing the symptoms of functional dyspepsia (Micklefield, Jung, Greving, \& May, 2003). Spirling and Daniels suggested that taking mint after meals could decrease gastrointestinal reactions and relieve the symptoms of dyspepsia (such as flatulence, belching, and abdominal distention) and colon spasms (Spirling \& Daniels, 2001).

This, however, was the first study to compare the effects of cumin, peppermint, and magnesium hydroxide on gastrointestinal complications after Cesarean section. Based on our findings, all three medicines could significantly decrease gastrointestinal complications. However, no significant difference was observed between groups. In other words, the positive effects of cumin and peppermint on gastrointestinal complications after Cesarean section were similar to those of MOM, a routine medicine in postoperative care after Cesarean section.

Based on these findings, due to their fewer side effects and equal benefits, herbal medicines, such as cumin and peppermint, can serve as helpful alternatives for pharmaceutical products such as MOM.

The present study had several limitations including the small number of participants in each group and the detectable taste of medicines (which might have turned the study into a single-blind trial). Therefore, future studies are recommended to recruited greater numbers of patients through more accurate sampling methods and to use relevant flavors to mask the taste of herbs.

\section{Source(s) of Support}

The financial support of the Research Deputy of Islamic Azad University is acknowledged.

\section{Acknowledgement}

We hereby appreciate the cooperation and assistance provided by nurses and staff of the Gynaecology and Obstetrics Department of Imam Hospital in Sari. This trial was supported by the Department of Midwifery, Sari Medical Sciences Branch, Islamic Azad University, Sari, Iran.

\section{Competing Interests Statement}

The authors declare that there is no conflict of interests regarding the publication of this paper.

\section{References}

Abebe, W. (2002). Herbal medication: Potential for adverse interactions with analgesic drugs. Journal of Clinical Pharmacy and Therapeutics, 27(6), 391-401. http://dx.doi.org/10.1046/j.1365-2710.2002.00444.x

Agah, S., Taleb, A. M., Moeini, R., Gorji, N., \& Nikbakht, H. (2013). Cumin Extract for Symptom Control in Patients with Irritable Bowel Syndrome: A Case Series. Middle East Journal of Digestive Diseases, 5(4), 217. Retrieved from http://www.ncbi.nlm.nih.gov

Ahmad, N. S., Delavar, B., E, Z. H., Kazemipour, S., Mehryar, A., \& Naghavi, M. (2009). Caesarean section in the Islamic Republic of Iran: Prevalence and some socio demographic correlates. Retrieved from http://www.ncbi.nlm.nih.gov

Ait, M. L., Ait, M. H., Elabbadi, N., Bensalah, M., Gamouh, A., Aboufatima, R., ... Zyad, A. (2007). Anti tumor properties of blackseed (Nigella sativa L.) extracts. Braz J Med Biol Res, 40(6), 839-47. http://dx.doi.org/ 


\section{$10.1590 / \mathrm{S} 0100-879 \times 2006005000108$}

Akhlaghi, F., Pourjavad, M., Mansouri, A., Tara, F., \& Vahedian, M. (2008). Effect of gum chewing on prevention of post cesarean ileus Hayat, 14(2), 35-40.

Alam, M. S., Roy, P. K., Miah, A. R., Mollick, S. H., Khan, M. R., Mahmud, M. C., \& Khatun, S. (2013). Efficacy of Peppermint oil in diarrhea predominant IBS-a double blind randomized placebo-controlled study. Mymensingh Med J., 22(1), 27-30.

Al-Ghamdi, M. S. (2001). The anti-inflammatory, analgesic and antipyretic activity of Nigella sativa. $J$ Ethnopharmacol, 76(1), 45-8. http://dx.doi.org/10.1016/S0378-8741(01)00216-1

Ali, H., \& Blunden, G. (2003). Pharmacological and toxicological properties of Nigella sativa. Phytother Res, 17(4) 299-305. http://dx.doi.org/10.1002/ptr.1309

Al-Johar, D., Shinwari, N., Arif, J., Al-Sanea, N., Jabbar, A. A., El-Sayed, R., ... Al-Saleh, I. (2008). Role of Nigella sativa and a number of its antioxidant constituents towards azoxymethane-induced genotoxic effects and colon cancer in rats. Phytother Res, 22(10), 1311-23. http://dx.doi.org/10.1002/ptr.2487

Badakhsh, M. H., Seifoddin, M., Khodakarami, N., Gholami, R., \& Moghimi, S. (2012). Rise in cesareansection rate over a 30-year period in a public hospital in Tehran, Iran. Arch Iran Med, 15(1), 4-7.

Bahmani, M., Rafieian-Kopaei, M., Hassanzadazar, H., Saki, K., Karamati, S. A., \& Delfan, B. (2014). A review on most important herbal and synthetic antihelmintic drugs. Asian Pacific Journal of Tropical Medicine, 7 , S29-S33. http://dx.doi.org/10.1016/S1995-7645(14)60200-5

Bamosa, A. O., Ali, B. A., \& Al-Hawsawi, Z. A. (2002). The effect of thymoquinone on blood lipids in rats. Indian J Physiol Pharmacol, 46(2), 195-201. PMID: 12500494. Retrieved from http://www.ncbi.nlm.nih.gov

Bandaranayake, W. M. (2006). Quality control, screening, toxicity, and regulation of herbal drugs. Modern phytomedicine: Turning medicinal plants into drugs, 25-58. http://dx.doi.org/10.1002/9783527609987.ch2

Bani, S., Seyed, R. A., Shams, G. T., Ghojazadeh, M., \& Hassanpour, S. (2010). Delivery Agents Preferences Regarding Mode of Delivery for Themselves and Pregnant Women (Obstetrics, Gynecologists, Midwives). $J$ of Nurs and Midwi, 18(5), 40-48. Retrieved from http://En.journals.sid.ir/viewpaper.aspx?ID=260228

Cappello, G., Spezzaferro, M., Grossi, L., Manzoli, L., \& Marzio, L. (2007). Peppermint oil (Mintoil $\left.{ }^{\circledR}\right)$ in the treatment of irritable bowel syndrome: A prospective doubleblind placebo-controlled randomized trial. Digestive and liver disease, 39(6), 530-6. http://dx.doi.org/10.1016/j.dld.2007.02.006

Chand, K., Jain, M., \& Jain, S. (2000). Alternaria spp. associated with cumin (Cuminum cyminum L.) seeds, their pathogenicity and control. Journal of Mycology and Plant Pathology, 30(1), 123-5. Retrieved from http://www.cabdirect.org/abstracts/20001006767.html

Dehkordi, F. R., \& Kamkhah, A. F. (2008). Antihypertensive effect of Nigella sativa seed extract in patients with mild hypertension. Fundam Clin Pharmacol, 22(4), 447-52. http://dx.doi.org/10.1111/j.1472-8206. 2008.00607.x

Fazel, N., Esmaeili, H., \& Razavi, N. (2013). Effect of cumin oil on post partum hemorrhage after cesarean. Iranian Journal of Medicinal and Aromatic Plants, 29(1), Pe97-Pe103. Retrieved from http://En4.23-En.journals.sid.ir/viewpaper.aspx?ID=307497

Hasani-Ranjbar, S., Larijani, B., \& Abdollahi, M. (2009). A systematic review of the potential herbal sources of future drugs effective in oxidant-related diseases. Inflammation \& Allergy-Drug Targets (Formerly Current Drug Targets-Inflammation \& Allergy), 8(1), 2-10. http://dx.doi.org/10.2174/187152809787582561

Hepner, D. L., Harnett, M., Segal, S., Camann, W., Bader, A. M., \& Tsen, L. C. (2002). Herbal medicine use in parturients. Anesthesia \& Analgesia, 94(3), 690-3. http://dx.doi.org/10.1097/00000539-200203000-00039

Herro, E., \& Jacob, S. E. (2010). Mentha piperita (peppermint). Dermatitis, 21(6), 327-9. Retrieved from http://www.ncbi.nlm.nih.gov

Hirayama, I., Suzuki, M., Ide, M., Asao, T., \& Kuwano, H. (2006). Gum-chewing stimulates bowel motility after surgery for colorectal cancer. Hepatogastroenterology, 53(68), 206-8.

Holst. L., Wright, D., Haavik, S., \& Nordeng, H. (2009). The use and the user of herbal remedies during pregnancy. The Journal of Alternative and Complementary Medicine, 15(7), 787. http://dx.doi.org/10.1089/ acm.2008.0467 
Hopkins, K. (2000). Are Brazilian women really choosing to deliver by Cesarean? So Sci and Med, 51(5), 725-740. http://dx.doi.org/10.1016/S0277-9536(99)00480-3

Kaleem, M., Kirmani, D., Asif, M., Ahmed, Q., \& Bano, B. (2006). Biochemical effects of Nigella sativa L seeds in diabetic rats. Indian $J$ Exp Biol, 44(9), 745-8. PMID: 16999030. Retrieved from http://www.ncbi.nlm.nih.gov

Kanter, M., Coskum, O., \& Uysal, H. (2006). The antioxidative and antihistaminic effect of Nigella sativa and its major constituent, thymoquinone on ethanol-induced gastric mucosal damage. Arch Toxicol, 80(4), 217-24. http://dx.doi.org/10.1007/s00204-005-0037-1

Khattab, M. M., \& Nagi, M. N. (2007). Thymoquinone supplementation attenuates hypertension and renal damage in nitric oxide deficient hypertensive rats. Phytother Res, 21(5), 410-4. http://dx.doi.org/10.1002/ ptr.2083

Kingham, J. (1995). Peppermint oil and colon spasm. The Lancet, 346(8981), 986. http://dx.doi.org/10.1016/ S0140-6736(95)91684-9

Koocheki, A., Nadjafi, F., et al. (2003). The status of medicinal and aromatic plants in Iran and strategies for sustainable utilization. Abstract book of the 3rd world congress on medicinal and aromatic plants for human welfare. Retrieved from http://medplant.ir/..../the -ststus-of-medicinal-and-aromatic-pI

Liu, J.-H., Chen, G.-H., Yeh, H.-Z., Huang, C. K., \& Poon, S.-K. (1997). Enteric Cesarean coated peppermint-oil capsules in the treatment of irritable bowel syndrome: A prospective, randomized trial. Journal of gastroenterology, 32(6), 765-8. http://dx.doi.org/10.1007/BF02936952

Maton, P. N., \& Burton, M. E. (1999). Antacids revisited: A review of their clinical pharmacology and recommended therapeutic use. Drugs, 57(6), 855-70. http://dx.doi.org/10.2165/00003495-19995706000003

McKay, D. L., \& Blumberg, J. B. (2006). A review of the bioactivity and potential health benefits of peppermint tea (Mentha piperita L.). Phytotherapy Research, 20(8), 619-33. http://dx.doi.org/10.1002/ptr.1936

Meddah, B., Ducroc, R., El Abbes, F. M., Eto, B., Mahraoui, L., Benhaddou-Andaloussi, A., ... Haddad, P. S. (2009). Nigella sativa inhibits intestinal glucose absorption and improves glucose tolerance in rats. $J$ Ethnopharmacol, 121(3), 419-24. http://dx.doi.org/10.1016/j.jep.2008.10.040

Menacker, F., \& Hamilton, B. E. (2010). Recent trends in cesarean delivery in the United States. NCHS Data Brief, (35), 1-8. PubMed: 20334736. Retrieved from http://www.ncbi.nlm.nih.gov/pub...

Micklefield, G., Jung, O., Greving, I., May, B. (2003). Effects of intraduodenal application of peppermint oil (WS(R)1340) and caraway oil (WS(R)1520) on gastroduodenal motility in healthy volunteers. Phytother Research, 17(2), 135-40. http://dx.doi.org/10.1002/ptr.1089

Ministry of Health and Medical Education Report, Department of Medication and Treatment, Investigation of Cesarean Delivery and Promotion of Vaginal Delivery in the Country. (2014). Retrieved from http://www.advbiores.net/article.asp?ISSN=2277-9175

Mohammaditabar, S., Kiani, A., \& Heydari, M. (2009). The survey on tendencies of Primiparous women for selecting the mode of delivery. Babol Uni of Med Sci J, 11(50), 54-59. [in Persian]. Retrieved from http://www.sid.ir/fa/vewssid/j-pdf/65813885009.pdf

Murray, S. (2000). Relation between private health insurance and high rates of caesarean section in Chile: Qualitative and quantitative study. BMJ, 321(7275), 1501-1505. http://dx.doi.org/10.1136/bmj.321.7275. 1501

Okeola, O. A., Adaramoye, C. M. N., Catherine, O., \& Falade, E. O. (2011). Antimalarial and antioxidant activities of methanolic extract of Nigella sativa seeds (black cumin) in mice infected with Plasmodium yoelli nigeriensis \& Olusegun G. Ademowo 2011-Springer. Parasitol Res, 108(6), 1507-12. http://dx.doi. org/10.1007/s00436-010-2204-4

Osterman, M. J., \& Martin, J. A. (2013). Changes in cesarean delivery rates by gestational age: United States, 1996-2011. NCHS Data Brief, (124), 1-8. Retrieved from http://www. ncbi.nlm.nih.gov

Potter, P. A., \& Perry, A. G. (2010). Canadian fundamentals of nursing: Mosby/Elsevier. Retrieved from http://www.elsevier.ca/ISBN/9781926648538/

Saad, B., Azaizeh, H., \& Said, O. (2008). Arab herbal medicine. Botanical Medicine in Clinical Practice, 4, 31. 
Retrieved from http://beleafherbal.com/public

Sakhavar, N., \& Mirteymouri, M. (2009). Comparison of cuminum cyminum with milk of magnesia in prevention of gastrointestinal discomforts after emergent cesarean section. JBUMS, 10, 42-8. Retrieved from Http://en.journals.sid.ir/viewPaper.aspx?ID=169477

Shareferad, G., Fathean, Z., Terane, M., \& Mahake, B. (2007). The Survey of pregnant women views about delivery and cesarian According Behavioral intention model. Elam Uni Med Sci J, 15(1), 19-23. [in Persian]. Retrieved from http://www.ncbi.nlm.nih.gov

Singh, K., \& Goswami, T. (1998). Mechanical properties of cumin seed (Cuminum cyminum Linn.) under compressive loading. Journal of Food Engineering, 36(3), 311-21. http://dx.doi.org/10.1016/S0260-8774 (98)00056-9

Spirling, L. I., \& Daniels, I. R. (2001). Botanical perspectives on health peppermint: More than just an after-dinner mint. The Journal of the Royal Society for the Promotion of Health, 121(1), 62-3. http://dx.doi.org/10.1177/146642400112100113

Torkzahrani, S. (2008). Commentary: Childbirth education in Iran. J Perinat Educ, 17(3), 51-54. http://dx.doi. org/10.1624/105812408X329601

Uz, E., Bayrak, O., Uz, E., Kaya, A., Bayrak, R., Uz, B., ... Akcay, A. (2008). Nigella sativa oil for prevention of chronic cyclosporine nephrotoxicity: An experimental model. Am J Nephrol, 28(3), 517-22. http://dx.doi. org/10.1159/000114004

Yaghmaei, M., Arbabi, F. K., Mokhtari, M., \& Behzadian, A (2009). Comparison of oral intake profiles at 2 and 8 hours following cesarean section under spinal anesthesia. JRMS, 11(4), 43-51.

Zoorob, G. K. (2012). Herbal preparation to relieve inflammation and smooth muscle contraction. Google Patents. Retrieved from http://www.google.com/patents/US8226987

\section{Copyrights}

Copyright for this article is retained by the author(s), with first publication rights granted to the journal.

This is an open-access article distributed under the terms and conditions of the Creative Commons Attribution license (http://creativecommons.org/licenses/by/3.0/). 